\title{
Role of Inferior Vena Cava Parameters as Predictors of Fluid Responsiveness in Pediatric Septic Shock: A Prospective Study
}

\author{
Ahmed Ahmed EL-Nawawy ${ }^{1}$ Omneya Magdy Omar ${ }^{2}$ Hadir Mohamed Hassouna ${ }^{1}$ \\ 1 Pediatric Intensive Care Unit, Department of Pediatrics, Faculty of \\ Address for correspondence Hadir Mohamed Hassouna, PhD, MD, \\ Medicine, Alexandria University, Egypt \\ 2 Department of Pediatrics, Faculty of Medicine, Alexandria \\ University, Egypt \\ Pediatric Intensive Care Unit, Department of Pediatrics, Faculty of \\ Medicine, Alexandria University, 2 Omar Zafaan Street, \\ El-Ibrahymia, Alexandria, Egypt \\ (e-mail: hadirelrouby@yahoo.com; hadir.hassouna@alexmed.edu.eg).
}

J Child Sci 2021;11:e49-e54

\begin{abstract}
\section{Keywords}

- distensibility index

- echocardiography

- fluid responsiveness

- inferior vena cava

- pediatric septic shock

Fluid resuscitation is the initial therapy for septic shock worldwide. Prediction of fluid responsiveness is essential for optimizing fluid administration. Only few pediatric studies have evaluated the role of inferior vena cava (IVC) as a reliable predictor of fluid responsiveness. The aim of this study was to evaluate the role of IVC parameters as predictors of fluid responsiveness in children (under the age of 5 years) having septic shock at different times from admission. A prospective observational study included 51 children having septic shock. It was conducted in the nine-bedded pediatric intensive care unit of a university hospital from January 1, 2018, to the August 31, 2018. Echocardiography was used to assess minimal and maximal IVC diameters and its distensibility index with simultaneous assessment of stroke volume (SV), at 1, 6, and 24 hours from admission. The decision to give fluid in these children was thereby based on the presence of at least one sign of inadequate tissue perfusion. SV was reassessed directly after administration of a fluid bolus of $10 \mathrm{~mL} / \mathrm{kg}$ over 10 minutes. Fluid responsiveness was considered adequate when there was $\geq 10 \%$ increase in SV after fluid bolus. Minimal IVC diameter indexed to body surface area and its distensibility index can be predictors of fluid responsiveness at all times: 1 hour (area under curve $[A \cup C]=0.88 ; 95 \%$ confidence interval $[\mathrm{Cl}]=0.77-0.96)$, 6 hours $(A \cup C=0.86 ; 95 \%$ $\mathrm{Cl}=0.67-0.97$ ), and 24 hours ( $\mathrm{AUC}=0.77 ; 95 \% \mathrm{Cl}=0.6-0.95$ ). IVC distensibility index can also predict fluid responsiveness at 1 hour ( $A \cup C=0.87 ; 95 \% \mathrm{Cl}=0.74-0.95$ ), 6 hours ( $A \cup C=0.86 ; 95 \% \mathrm{Cl}=0.73-0.94$ ), and 24 hours ( $A \cup C=1 ; 95 \% \mathrm{Cl}=0.77-1$ ). The cutoff points of each parameter differed from time to time (contradicts with previous statement that says it is predictor at all times). The maximum IVC diameter could not predict fluid responsiveness at any time from admission. Minimal IVC diameter and its distensibility index were feasible noninvasive surrogates of fluid responsiveness in pediatric septic shock at different times from admission.
\end{abstract}

received

October 12, 2020

accepted after revision

January 12, 2021
DOI https://doi.org/

$10.1055 / \mathrm{s}-0041-1724034$.

ISSN 2474-5871. (c) 2021. The Author(s).

This is an open access article published by Thieme under the terms of the Creative Commons Attribution License, permitting unrestricted use, distribution, and reproduction so long as the original work is properly cited. (https://creativecommons.org/licenses/by/4.0/)

Georg Thieme Verlag KG, Rüdigerstraße 14, 70469 Stuttgart, Germany 


\section{Introduction}

Worldwide, fluid therapy is the initial step in management of acute circulatory failure, the most common cause for which is sepsis. ${ }^{1}$ Hypovolemia is one of the components of circulatory failure in septic shock leading to tissue hypoperfusion and multiple organ failure. However, excess liquid expansion may result in fluid shifts into the extravascular space and cause damage through end-organ edema and dysfunction. Fluid overload increases length of hospital stay and mortality when corrected for disease severity. ${ }^{2,3}$ Thus, accurate assessment of intravascular volume status is mandatory for appropriate management of critically ill children. $^{3}$

The assessment of surrogates for ventricular preload and intravascular volume status, including central venous pressure, is poorly correlated or inaccurately measured by clinicians. Many of these surrogates for ventricular preload are invasive, time-consuming, and with considerable risks. ${ }^{4}$ Multiple adult studies have evaluated ultrasound examination of the inferior vena cava (IVC) as a noninvasive measure of preload. ${ }^{5}$ However, there are few studies in the literature investigating its role in pediatric populations. $^{6}$

Point-of-care ultrasound has been increasingly used in evaluating septic shock; including the measurement of IVC diameters and collapsibility/distensibility indices. ${ }^{7,8}$ As a collapsible major vein whose diameter is altered by respiration, blood volume, and right heart function, IVC works as a reservoir and reflects volume status. ${ }^{9,10}$

The American Society of Echocardiography recent guidelines support the general use of IVC size and collapsibility/ distensibility in the assessment of volume status. ${ }^{11}$ Repeated measurements during resuscitation help assess volume repletion. $8,10,12$

The rationale of the current study was to evaluate the accuracy of IVC parameters in predicting fluid responsiveness in critically ill children (under the age of 5 years) having septic shock at different times from pediatric intensive care unit (PICU) admission.

\section{Material and Method}

This prospective observational study was conducted in the nine-bedded PICU of a university teaching hospital from January 1, 2018, to August 31, 2018. Approval of the ethical committee and informed consent from the patients' parents/legal guardians were obtained. The current study was registered in the Cochrane Library under registration number PACTR201801002954243.

\section{Sample Size}

A sample size of 50 patients was calculated using the MedCalc Program (version 12.2.1.0) as the minimum required sample to detect an area under the receiver operating characteristic (ROC) curve of 0.75 , relative to a null value of 0.5 , as statistically significant with $90 \%$ power and at a level of significance of $95 \%(\alpha=0.05) .^{13}$

\section{Pilot Study}

A pilot study was performed prior to the current study incorporating 12 patients. It showed an excellent degree of intraobserver and interobserver reliability in the three baseline measurements of stroke volume(SV). The intraclass correlation coefficients (ICC) were high for both intraobserver and interobserver comparisons. The ICC of the average measure of SV was 0.94 (95\% confidence interval $[\mathrm{CI}]=0.91-0.96 ; p<0.001$ ) and $0.92(95 \% \mathrm{CI}=0.91-0.94 ; p<0.001)$ for intraobserver and interobserver comparisons, respectively. For IVC measurements, intraobserver ICC were $0.99(95 \% \mathrm{CI}=0.97-1.00$; $p<0.001)$ and $0.99(95 \% \mathrm{Cl}=0.98-0.99 ; p<0.001)$ for minimal and maximum IVC diameters, respectively. The interobserver ICC were $0.98(95 \% \mathrm{CI}=0.97-0.99 ; p<0.001)$ and $0.97(95 \%$ $\mathrm{Cl}=0.96-0.99 ; p<0.001)$ for minimal and maximum IVC diameters, respectively.

\section{Eligibility Criteria}

Patients from 1 month to 5 years were eligible if they had septic shock on admission to the PICU, as defined by the American College of Critical Care Medicine and International Pediatric Sepsis Consensus. ${ }^{14,15}$ All included patients were mechanically ventilated on the first day of admission according to the current pediatric sepsis guidelines as detailed in the pediatric section of Surviving Sepsis Campaign (SSC). ${ }^{16}$

\section{Exclusion Criteria}

Children with congenital heart disease and viral myocarditis, as confirmed by a pediatric cardiologist, were excluded. Patients with intra-abdominal mass, ascites, cardiothoracic or abdominal surgery, or on peritoneal dialysis were also excluded.

\section{Protocol of the Study}

Transthoracic echocardiography was performed using Philips HD 11XE system (Philips 989605325131, USA) at 1, 6 , and 24 hours from admission. The decision to give fluid in these children was taken based on the presence of at least one sign of inadequate tissue perfusion, such as: (1) tachycardia, defined as a mean heart rate $>2$ standard deviation (SD) above normal for age; (2) decrease in blood pressure $<5$ th percentile or systolic blood pressure $<2$ SD below normal for age; (3) urine output $<0.5 \mathrm{~mL} / \mathrm{kg} / \mathrm{h}$; and (4) prolonged capillary refill $>5$ seconds. Patients could be included more than once at different times in the study. Echocardiography was performed by a 5-year experienced operator who received adequate training courses on functional echocardiography for an intensivist. All results were reviewed by a pediatric cardiology consultant who was blinded to the clinical condition of the studied patients and the purpose of the study.

In supine position, IVC was assessed in the anteroposterior plane in the subxiphoid view using two-dimensional mode till an optimal view of IVC entering the right atrium was obtained. ${ }^{8,12}$ Then, M-mode line was placed perpendicularly through the IVC just caudal to the hepatic vein confluence. After freezing M-mode, the caliber of the maximum and the minimum diameters of the IVC were 


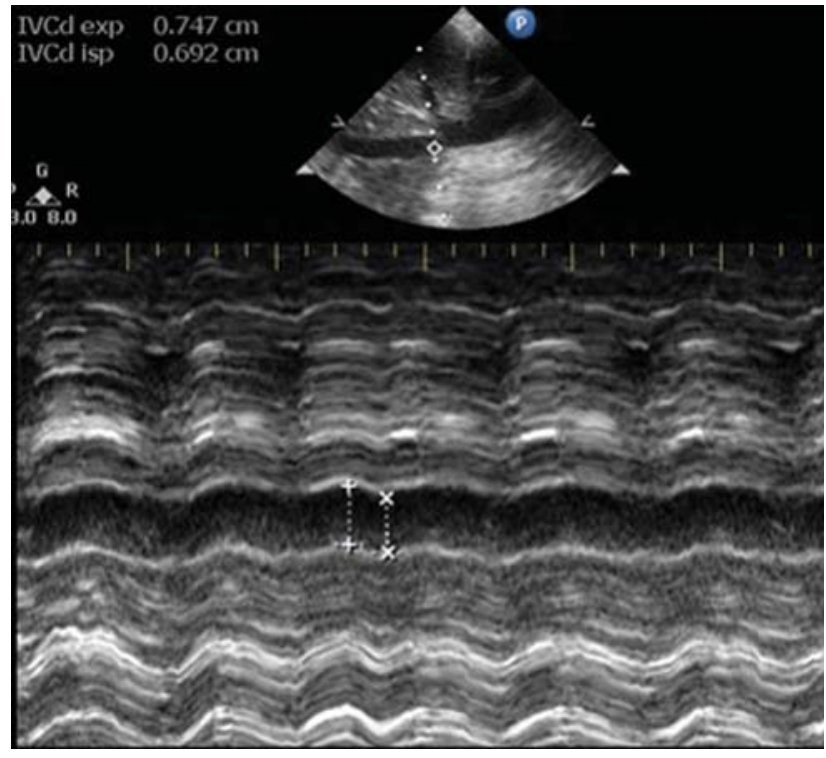

Fig. 1 Inferior vena cava measured by echocardiography.

measured (-Fig. 1). Measurements were indexed to body surface area (BSA). Since all patients were mechanically ventilated at the time of performance of echocardiography, IVC distensibility index (IVCDI) was used. It was calculated as: ([maximum IVC diameter - minimum IVC diameter]/ minimum IVC diameter $) \times 100 .{ }^{17}$ IVC measurements were performed in triplicate over three consecutive respiratory cycles and then averaged.

The standard fluid challenge was then performed in which a fluid bolus of $10 \mathrm{~mL} / \mathrm{kg}$ was administered over 10 minutes. Ventilator settings as well as infusion rates of inotropic/vasopressor agents were held constant during fluid bolus administration. SV was assessed immediately before and after fluid challenge using echocardiography. In the left parasternal view, the diameter of the aorta was measured at the level of the aortic valve insertion. The left ventricular outflow tract (LVOT) area was measured using the following equation: (LVOT area $=0.785 \times$ [diameter of the aorta at the level of annuls]), calculated by the device. ${ }^{2}$ Velocity time integral (VTI) of aortic blood flow is equivalent to the product of the mean velocity (obtained by tracing the spectrum of LVOT flow) and ejection time. Pulsed-wave Doppler signal from the five chambers' apical view was directed parallel to flow through the LVOT below the aortic valve and the velocity was recorded $(\mathrm{cm} / \mathrm{s})$. The SV was calculated by the device using the equation: $(\mathrm{SV}=\mathrm{VTI} \times$ LVOT area). According to previous studies, we adopted that $10 \%$ or more increase in SV was valid to signify fluid responsiveness. ${ }^{18,19}$

\section{Statistical Methods}

Data were collected and entered to the computer using SPSS -Statistical Package for Social Science-program for statistical analysis (version 21). The area under the ROC curve was carried using MedCalc Software version 14. Youden index was used to determine the best cutoff value.

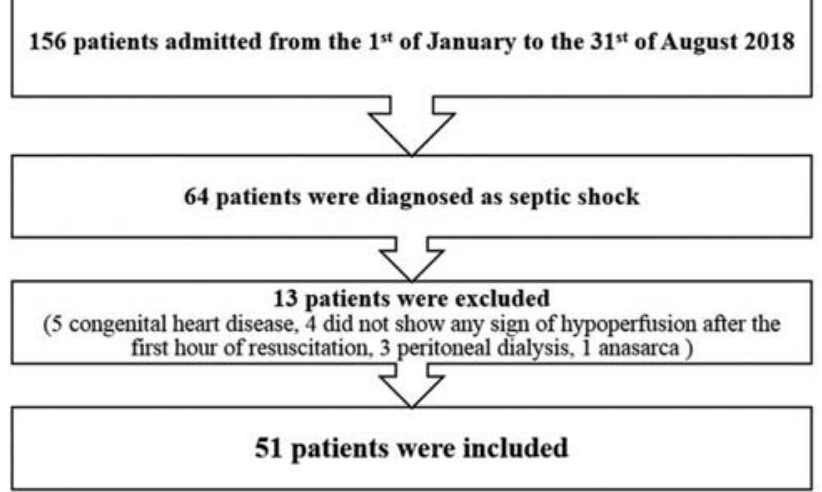

Fig. 2 Recruitment and screening of study patients.

\section{Results}

There were 156 patients admitted from January 1, 2018, to August 31,2018. Sixty-four patients were diagnosed as septic shock. Thirteen patients were excluded as per exclusion criteria or incomplete data. Thus, 51 patients were studied (-Fig. 2).

- Table 1 presents the demographic data, initial assessment, and outcome of patients. - Table 2 shows timely recorded hemodynamic variables with IVC measurements at 1,6 , and 24 hours from admission. Among children for whom the decision to give fluid was taken, responders were $88.2 \%(45 / 51), 64 \%(16 / 25)$, and $57 \%(8 / 14)$ at 1,6 , and 24 hours from admission, respectively.

At 1 hour from admission, minimal IVC/BSA with a cutoff point of $\leq 0.93 \mathrm{~cm} / \mathrm{m}^{2}$ was an excellent discriminator of fluid responsiveness with area under curve $($ AUC $)=0.88(95 \%$ $\mathrm{CI}=0.77-0.96$ ). Also, IVCDI at 1 hour with a cutoff point of $>12.23 \%$ was an excellent discriminator of fluid responsiveness with $\mathrm{AUC}=0.87$ (95\% $\mathrm{CI}=0.74-0.95)$. Minimal IVC/BSA of $\leq 1.15 \mathrm{~cm} / \mathrm{m}^{2}$ and IVCDI of $>15.86 \%$ were excellent discriminators of fluid responsiveness at 6 hours from admission (AUC $=0.86[95 \% \mathrm{CI}=0.67-0.97]$ and 0.86 [95\% $\mathrm{CI}=0.73-0.94]$ respectively). At 24 hours from admission, minimal IVC/BSA with a cutoff point of $\leq 0.97 \mathrm{~cm} / \mathrm{m}^{2}$ was considered an acceptable discriminator of fluid responsiveness with AUC of $0.77(95 \% \mathrm{CI}=0.6-0.95)$. IVCDI with a cutoff point of $>22.57 \%$ was also an outstanding discriminator of fluid responsiveness with $A U C=1(95 \% \mathrm{CI}=0.77-1)$. Notably, maximal IVC/BSA was not a significant discriminator of fluid responsiveness at any time from admission (-Table 3).

\section{Discussion}

Intravenous fluid is the cornerstone in the management of pediatric septic shock, aiming to reverse organ dysfunction. ${ }^{14,15}$ Echocardiography is crucial for guiding fluid resuscitation in critically ill patients to avoid the injurious effect of inappropriate use of fluid. $8,11,12,18$

In the present study, children for whom the decision to give fluid was taken decreased with time due to volume 
Table 1 Demographic data, initial assessment, and outcomes

\begin{tabular}{|c|c|c|c|}
\hline Age (months) ${ }^{a}$ & $6(2-15)$ & $\mathrm{PIM}^{\mathrm{a}}$ & $61.2(40.5-74.7)$ \\
\hline Weight $(\mathrm{kg})^{\mathrm{a}}$ & $6.8(4.4-12)$ & PELOD day $1^{\mathrm{b}}$ & $26.4(16.3)$ \\
\hline Height $(\mathrm{cm})^{\mathrm{a}}$ & $65.5(55.4-74.6)$ & Mechanical ventilation: $n(\%)$ & $41(80.4 \%)$ \\
\hline \multicolumn{2}{|l|}{ Sex: $n(\%)$} & Type of shock: $n(\%)$ & \\
\hline $\begin{array}{l}\text { Male } \\
\text { Female }\end{array}$ & $\begin{array}{l}29(56.8 \%) \\
22(43.2 \%)\end{array}$ & $\begin{array}{l}\text { Warm shock } \\
\text { Cold shock }\end{array}$ & $\begin{array}{l}22(43.13 \%) \\
29(56.8 \%)\end{array}$ \\
\hline 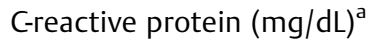 & $35.5(22.3-79)$ & Shock reversed: $n(\%)$ & $42(82.4 \%)$ \\
\hline DIC score ${ }^{a}$ & $6(4-6)$ & Shock reversal time $^{\mathrm{d}}$ (hours) $^{\mathrm{a}}$ & $72(36-96)$ \\
\hline \multicolumn{2}{|l|}{ Source of infection: $n(\%)^{c}$} & Length of PICU stay (days) $^{\mathrm{a}}$ & $8(6-10)$ \\
\hline Blood stream infection & $40(78.4 \%)$ & \multicolumn{2}{|l|}{ Fate: $n(\%)$} \\
\hline Pneumonia & $27(52.9 \%)$ & Survived & 39 (76.5\%) \\
\hline Abdominal infection & $24(47 \%)$ & Deceased & $12(23.5 \%)$ \\
\hline Meningitis & $14(27.4 \%)$ & & \\
\hline Urosepsis & $2(3.9 \%)$ & & \\
\hline
\end{tabular}

Abbreviations: DIC, disseminated intravascular coagulopathy; PELOD, pediatric logistic organ dysfunction; PICU, pediatric intensive care unit; PIM2, Pediatric Index of Mortality 2; SBP, systolic blood pressure.

${ }^{a}$ Median (interquartile range).

${ }^{\mathrm{b}}$ Mean (standard deviation).

'Patients could have more than one condition.

${ }^{\mathrm{d}}$ Shock reversal time is defined as maintenance of systolic blood pressure (SBP) $<5$ th percentile for age or $>70 \mathrm{~mm} \mathrm{Hg}$ from 1 month to 1 year (age $\times 2+70$ ), from 1 to 10 years, and SBP of at least $90 \mathrm{~mm} \mathrm{Hg}$ in children $>10$ years, without vasopressor support for at least 24 hours.

Table 2 Timely recorded hemodynamic variables

\begin{tabular}{|c|c|c|c|}
\hline & 1 hour $(n=51)$ & 6 hours $(n=25)$ & 24 hours $(n=14)$ \\
\hline Systolic blood pressure $(\mathrm{mm} \mathrm{Hg})$ & $90(89-110)$ & $100(90-112)$ & $105(99-110)$ \\
\hline Mean arterial pressure (MAP; mm Hg) & $62.5(58-73)$ & $69.5(59-78)$ & $77(72-80)$ \\
\hline Heart rate (beats/min) & $162(155-180)$ & $177(160-184)$ & $156(142-180)$ \\
\hline Central venous pressure (CVP; $\left.\mathrm{cmH}_{2} \mathrm{O}\right)$ & $7.36(5.8-9.5)$ & $11.5(8.8-11.7)$ & $10.3(9.5-11.8)$ \\
\hline Central oxygen venous saturation (\%) & $58(44-62)$ & $62(51-69)$ & $65(59-63)$ \\
\hline MAP-CVP $(\mathrm{mm} \mathrm{Hg})^{*}$ & $56(50.2-65.4)$ & $57(50.7-68.4)$ & $65.4(59.3-69.7)$ \\
\hline Lactate $(\mathrm{mmol} / \mathrm{L})$ & $2.4(2.2-3.7)$ & $1.8(1.4-2.00)$ & $1.5(1.2-2.0)$ \\
\hline Urine output $(\mathrm{mL} / \mathrm{kg} / \mathrm{h})$ & $0.5(0.4-1.5)$ & $1.9(1-2.5)$ & $2.3(1.8-3.3)$ \\
\hline Cumulative fluid (mL/kg) & $60(60-80)$ & $80(60-80)$ & $80(60-100)$ \\
\hline \multicolumn{4}{|l|}{ Inferior vena cava measurements } \\
\hline Minimal IVC diameter $(\mathrm{cm})$ & $0.4(0.3-0.45)$ & $0.41(0.33-0.5)$ & $0.45(0.4-0.55)$ \\
\hline Minimal IVC diameter/BSA $\left(\mathrm{cm} / \mathrm{m}^{2}\right)$ & $1.18(0.85-1.53)$ & $1.15(0.97-1.62)$ & $1.44(1.04-1.97)$ \\
\hline Maximal IVC diameter $(\mathrm{cm})$ & $0.58(0.5-0.66)$ & $0.61(0.55-0.68)$ & $0.62(0.59-0.68)$ \\
\hline Maximal IVC diameter/BSA $\left(\mathrm{cm} / \mathrm{m}^{2}\right)$ & $1.83(1.34-2.16)$ & $1.9(1.6-2.42)$ & $1.91(1.67-2.53)$ \\
\hline IVCDI & $12(5-31.3)$ & $15.15(7.3-23)$ & $17.8(5-33.2)$ \\
\hline
\end{tabular}

Abbreviations: BAS, body surface area; IVC, inferior vena cava; IVCDI, inferior vena cava distensibility index.

Note: Data presented as median (interquartile range); $n=$ number of patients for whom the decision to give fluid was taken based on the presence of at least one sign of inadequate tissue perfusion.

"Perfusion pressure which is the difference between mean arterial pressure and central venous pressure.

restoration. Also, the number of responders among those in apparent need of fluid diminished progressively. This is probably due to the development of septic myocardial dysfunction, as a result of the restoration of the left ventricular pre/afterload or due to the natural evolution of the infectious process. $^{20}$ Therefore, repeating serial echocardiography at different times is crucial to unmask poor intrinsic left ventricular contractility. ${ }^{8}$ Boyd et al have stated that twothirds of patients will be fluid unresponsive following an initial volume resuscitation of $30 \mathrm{~mL} / \mathrm{kg} .{ }^{21}$ This encourages the use of other hemodynamic therapies, such as inotrope infusion.

In the current study, IVC parameters were compared with the standard fluid challenge test as surrogates for fluid 
Table 3 Receiver operating characteristics curve of the inferior vena cava parameters as predictors of fluid responsiveness

\begin{tabular}{|c|c|c|c|c|c|c|c|}
\hline & AUC $(95 \% \mathrm{CI})$ & $Z$ (p-value) & $\begin{array}{l}\text { Cutoff } \\
\text { value }^{(\mathrm{YI})}\end{array}$ & $\begin{array}{l}\text { Sensitivity: } \\
\text { (95\% CI) }\end{array}$ & $\begin{array}{l}\text { Specificity: } \\
(95 \% \mathrm{Cl})\end{array}$ & $\begin{array}{l}\text { PPV (\%): } \\
\text { (95\% Cl) }\end{array}$ & $\begin{array}{l}\text { NPV (\%): } \\
\text { (95\% CI) }\end{array}$ \\
\hline IVC min/BSA $1 \mathrm{~h}$ & $0.88(0.77-0.96)$ & $7.89\left(<0.0001^{*}\right)$ & $\leq 0.93 \mathrm{~cm} / \mathrm{m}^{2}$ & $\begin{array}{l}70 \\
(45.7-88.1)\end{array}$ & $\begin{array}{l}100 \\
(88.4-100)\end{array}$ & $\begin{array}{l}100 \\
(76.8-100)\end{array}$ & $\begin{array}{l}83.3 \\
(67.2-93.6)\end{array}$ \\
\hline IVC max/BSA $1 \mathrm{~h}^{\#}$ & $0.68(0.54-0.8)$ & $2.2(0.26)$ & - & - & - & - & - \\
\hline IVCDI $1 \mathrm{~h}$ & $0.87(0.74-0.95)$ & $6.55\left(<0.0001^{*}\right)$ & $>12.32 \%$ & $\begin{array}{l}85 \\
(62.1-96.8)\end{array}$ & $\begin{array}{l}76.67 \\
(57.2-90.1)\end{array}$ & $\begin{array}{l}70.8 \\
(48.9-87.4)\end{array}$ & $\begin{array}{l}88.5 \\
(69.8-97.6)\end{array}$ \\
\hline IVC min/BSA $6 \mathrm{~h}$ & $0.86(0.67-0.97)$ & $4.67\left(<0.0001^{*}\right)$ & $\leq 1.15 \mathrm{~cm} / \mathrm{m}^{2}$ & $\begin{array}{l}92.86 \\
(66.1-99.8)\end{array}$ & $\begin{array}{l}72.7 \\
(39-94)\end{array}$ & $\begin{array}{l}81.2 \\
(54.4-96)\end{array}$ & $\begin{array}{l}88.9 \\
(51.8-99.7)\end{array}$ \\
\hline IVC max/BSA $6 \mathrm{~h}^{\#}$ & $0.59(0.44-0.72)$ & $1.01(0.32)$ & - & - & - & - & - \\
\hline IVCDI $6 \mathrm{~h}$ & $0.86(0.73-0.94)$ & $4.72\left(<0.0001^{*}\right)$ & $>15.86 \%$ & $\begin{array}{l}78.6 \\
(49.2-95.2)\end{array}$ & $\begin{array}{l}94.4 \\
(81.3-99.3)\end{array}$ & $\begin{array}{l}84.6 \\
(585-95.6)\end{array}$ & $\begin{array}{l}91.9 \\
(80.6-96.9)\end{array}$ \\
\hline IVC min/BSA $24 \mathrm{~h}$ & $0.77(0.6-0.95)$ & $1.98\left(0.047^{*}\right)$ & $\leq 0.97 \mathrm{~cm} / \mathrm{m}^{2}$ & $\begin{array}{l}75.4 \\
(34.9-96.2)\end{array}$ & $\begin{array}{l}83.33 \\
(35.9-99.6)\end{array}$ & $\begin{array}{l}85.7 \\
(42.1-99.6)\end{array}$ & $\begin{array}{l}71.4 \\
(29.3-96.3)\end{array}$ \\
\hline IVC max/BSA $24 \mathrm{~h}^{\#}$ & $0.55(0.28-0.8)$ & $0.31(0.759)$ & - & - & - & - & - \\
\hline IVCDI 24 h & $1.00(0.77-1.00)$ & $N C\left(<0.0001^{*}\right)$ & $>22.57 \%$ & $\begin{array}{l}100 \\
(63.1-100)\end{array}$ & $\begin{array}{l}100 \\
(54.1-100)\end{array}$ & $\begin{array}{l}100 \\
(63.1-100)\end{array}$ & $\begin{array}{l}100 \\
(54.1-100)\end{array}$ \\
\hline
\end{tabular}

Abbreviations: AUC, area under the curve; BAS, body surface area; Cl, confidence interval; IVC, inferior vena cava; IVCDI, inferior vena cava distensibility index; NC, noncountable; NNV, negative predictive value; PPV, positive predictive value.

Y'Youden index

*Statistically significant at $p<0.05$

\#Nonsignificant discriminator of fluid responsiveness, so cutoff value could not be determined.

responsiveness. IVCDI with increasing specificity over time could correctly identify all fluid nonresponders suggesting that hemodynamic instability should be corrected by means other than fluid administration. Using a fluid challenge in these patients would be harmful due to deleterious effect of unnecessary fluid administration and volume overload. Thus, IVC parameters are simple, easy, and noninvasive bedside methods to predict fluid responsiveness without any risk of fluid overload in potential nonresponders.

Intubation and mechanical ventilation of infants and children having septic shock is recommended by Society of Critical Care Medicine's SSC guidelines to optimize oxygen delivery using lung protective stratigies. ${ }^{16}$ Positive-pressure ventilation affects the diameter and distensibility of the IVC. It increases the pleural and right atrial pressure values with reduction of the venous return to the heart by increasing the intrathoracic pressure during inspiration. IVC diameter expands during inspiration and contracts during expiration in an intubated patient, unlike in spontaneously breathing patients. Therefore, it is recommended to use IVCDI instead of the IVC collapsibility index in patients undergoing positive-pressure mechanical ventilation. Pediatric data are scarce, the IVCDI is a new term in pediatric practice, and its reference values have not been described well yet. ${ }^{22}$ IVCDI was used in the present study, as all patients were intubated on the first day of admission. IVCDI was an excellent discriminator of fluid responsiveness at all times of the study.

The current study is unique in the demonstration of the effect of time on obtained IVC parameters. The accuracy of IVC parameters, as well as their cutoff points, differed from one time to another. The cutoff points of IVCDI varied at different times according to the variable differences between minimal and maximal diameters of IVC. Dipti et al stated that the caval index seemed to gain greater accuracy with higher sensitivity in emergency department studies than ICU studies due to the transient effect, which was not observed in ICU. ${ }^{4}$

Maximum IVC diameter could not predict fluid responsiveness at any time from admission. This was similar to Ilyas et al who also found that there was no significant difference in maximal IVC diameter between the euvolemic and hypovolemic groups. $^{23}$

The evaluation of the IVC diameters and its respirophasic variation seem to be a well-studied method in adults with a high degree of heterogeneity in the results. ${ }^{1,6}$ However, very few pediatric studies have evaluated the role of IVC as a reliable predictor of fluid responsiveness. Obtaining conclusions from that small number of studies is very difficult. ${ }^{6}$ Similar to the current results, Zhang et al, who involved 235 patients from 8 studies, revealed that respiratory variation in IVC diameter could predict fluid responsiveness with pooled AUC of $0.84 .^{24}$ Bilgili et al utilized cutoff values of $>22.7 \%$ for IVCDI to predict fluid responsiveness in anesthetized pediatric patients undergoing urologic surgery. ${ }^{25}$ Other studies also revealed a good correlation between distensibility of the IVC and fluid overload in mechanically ventilated PICU patients. ${ }^{26}$ On the other hand, a meta-analysis by Long et al demonstrated that the pooled sensitivity and specificity for IVC parameters as predictors of fluid responsiveness were 0.63 and 0.73 , respectively, with a pooled AUC of $0.79 .^{1}$ Moreover, a meta-analysis by Orso et al revealed that ultrasound evaluation of the diameter of the IVC and its respiratory variations did not seem to be a reliable method to predict the fluid responsiveness with a pooled AUC of 0.71 , and sensitivity and specificity of 0.74 and 0.68 , respectively. ${ }^{6}$ The wide variation of results in different studies is due to differences in patient populations, definition and measurement technique for defining fluid responsiveness, the volume of the fluid challenge, and threshold change in IVC diameter. 
An important limitation of the study is that echocardiography may not be always available, in every institution, which restricts the generalizability of the study. Thus, appropriate training of PICU personnel is mandatory to ensure availability of this essential tool round the clock.

\section{Conclusions}

IVC minimal diameter and distensibility index are reliable, noninvasive, and easily measured parameters by intensivists that may be used to predict fluid responsiveness instead of more sophisticated methods such as SV changes, which need more expert personnel.

\author{
Funding \\ None.

\section{Conflict of Interest \\ None declared.}

\section{References}

1 Long E, Oakley E, Duke T, Babl FEPaediatric Research in Emergency Departments International Collaborative (PREDICT) Does respiratory variation in inferior vena cava diameter predict fluid responsiveness: a systematic review and meta-analysis? Shock 2017;47(05):550-559

2 Kelm DJ, Perrin JT, Cartin-Ceba R, Gajic O, Schenck L, Kennedy CC. Fluid overload in patients with severe sepsis and septic shock treated with early goal-directed therapy is associated with increased acute need for fluid-related medical interventions and hospital death. Shock 2015;43(01):68-73

3 Kathuria N, Ng L, Saul T, Lewiss RE. The baseline diameter of the inferior vena cava measured by sonography increases with age in normovolemic children. J Ultrasound Med 2015;34(06): 1091-1096

4 Dipti A, Soucy Z, Surana A, Chandra S. Role of inferior vena cava diameter in assessment of volume status: a meta-analysis. Am J Emerg Med 2012;30(08):1414-1419.e1

5 Corl K, Napoli AM, Gardiner F. Bedside sonographic measurement of the inferior vena cava caval index is a poor predictor of fluid responsiveness in emergency department patients. Emerg Med Australas 2012;24(05):534-539

6 Orso D, Paoli I, Piani A, et al. Accuracy of ultrasonographic measurements of inferior vena cava to determine fluid responsiveness: a systematic review and meta-analysis. J Intensive Care Med 2018. Doi: $10.1177 / 0885066617752308$

7 Abu-Zidan FM. Optimizing the value of measuring inferior vena cava diameter in shocked patients. World J Crit Care Med 2016;5 (01):7-11

8 El-Nawawy AA, Abdelmohsen AM, Hassouna HM. Role of echocardiography in reducing shock reversal time in pediatric septic shock: a randomized controlled trial. J Pediatr (Rio J) 2018;94 (01):31-39

9 Baker EC, Pott J, Khan F, Freund Y, Harris T. Best approach to measuring the inferior vena cava in spontaneously ventilating patients: a pilot study. Eur J Emerg Med 2015;22:58-61

10 Seif D, Mailhot T, Perera P, Mandavia D. Caval sonography in shock: a noninvasive method for evaluating intravascular volume in critically ill patients. J Ultrasound Med 2012;31(12): 1885-1890

11 Lang RM, Badano LP, Mor-Avi V, et al. Recommendations for cardiac chamber quantification by echocardiography in adults: an update from the American Society of Echocardiography and the European Association of Cardiovascular Imaging. Eur Heart J Cardiovasc Imaging 2015;16(03):233-270

12 Plant V, Vanguri P, Anand R, Haynes J, Aboutanos M, Ferrada P. Image-guided resuscitation with limited transthoracic echocardiogram in pediatric trauma patients. Pediatr Emerg Care 2018; 34(02):121-124

13 Charan J, Biswas T. How to calculate sample size for different study designs in medical research? Indian J Psychol Med 2013;35 (02):121-126

14 Goldstein B, Giroir B, Randolph AInternational Consensus Conference on Pediatric Sepsis. International pediatric sepsis consensus conference: definitions for sepsis and organ dysfunction in pediatrics. Pediatr Crit Care Med 2005;6(01):2-8

15 Brierley J, Carcillo JA, Choong K, et al. Clinical practice parameters for hemodynamic support of pediatric and neonatal septic shock: 2007 update from the American College of Critical Care Medicine. Crit Care Med 2009;37(02):666-688

16 Dellinger RP, Levy MM, Rhodes A, et al; Surviving Sepsis Campaign Guidelines Committee including The Pediatric Subgroup. Surviving Sepsis Campaign: international guidelines for management of severe sepsis and septic shock, 2012. Intensive Care Med 2013;39 (02):165-228

17 Barbier C, Loubières Y, Schmit C, et al. Respiratory changes in inferior vena cava diameter are helpful in predicting fluid responsiveness in ventilated septic patients. Intensive Care Med 2004;30 (09):1740-1746

18 Miller A, Mandeville J. Predicting and measuring fluid responsiveness with echocardiography. Echo Res Pract 2016;3(02): G1-G12

19 Assadi F. Passive leg raising: simple and reliable technique to prevent fluid overload in critically ill patients. Int J Prev Med 2017;8(01):48

20 Vieillard-Baron A, Caille V, Charron C, Belliard G, Page B, Jardin F Actual incidence of global left ventricular hypokinesia in adult septic shock. Crit Care Med 2008;36(06):1701-1706

21 Boyd JH, Sirounis D, Maizel J, Slama M. Echocardiography as a guide for fluid management. Crit Care 2016;20:274-280

22 Yildizdas D, Aslan N. Ultrasonographic inferior vena cava collapsibility and distensibility indices for detecting the volume status of critically ill pediatric patients. J Ultrason 2020;20(82):e205-e209

23 Ilyas A, Ishtiaq W, Assad S, et al. Correlation of IVC diameter and collapsibility index with central venous pressure in the assessment of intravascular volume in critically ill patients. Cureus 2017;9(02):e1025

24 Zhang Z, Xu X, Ye S, Xu L. Ultrasonographic measurement of the respiratory variation in the inferior vena cava diameter is predictive of fluid responsiveness in critically ill patients: systematic review and meta-analysis. Ultrasound Med Biol 2014;40(05): 845-853

25 Bilgili B, Haliloglu M, Tugtepe H, Umuroglu T. The assessment of intravascular volume with inferior vena cava and internal jugular vein distensibility indexes in children undergoing urologic surgery. J Invest Surg 2018;31(06):523-528

26 Basu S, Sharron M, Herrera N, Mize M, Cohen J. Point of care ultrasound assessment of the inferior vena cava in mechanically ventilated critically ill children. J Ultrasound Med 2020;39(08): 1573-1579 